\title{
BMJ Global Heath Collecting data for global surgical indicators: a collaborative approach in the Pacific Region
}

Glenn Douglas Guest, ${ }^{1}$ Elizabeth McLeod, ${ }^{1}$ William R G Perry, ${ }^{2}$ Vilami Tangi, ${ }^{3}$ Joao Pedro, ${ }^{3}$ Ponifasio Ponifasio, ${ }^{3}$ Johnny Hedson, ${ }^{1}$ Jemesa Tudravu, ${ }^{3}$ Douglas Pikacha, ${ }^{3}$ Eric Vreede, ${ }^{1}$ Basil Leodoro, ${ }^{3}$ Noah Tapaua, ${ }^{3}$ James Kong, ${ }^{1}$ Bwabwa Oten, ${ }^{3}$ Deacon Teapa, ${ }^{3}$ Stephanie Korin, ${ }^{1}$ Leona Wilson, ${ }^{4}$ Samson Mesol, ${ }^{3}$ Kabiri Tuneti, ${ }^{3}$ John G Meara, ${ }^{5}$ David A Watters ${ }^{1}$

To cite: Guest GD, McLeod E, Perry WRG, et al. Collecting data for global surgical indicators: a collaborative approach in the Pacific Region. BMJ Glob Health 2017;2:e000376. doi:10.1136/ bmjgh-2017-000376

Handling editor Seye Abimbola

Received 20 April 2017

Revised 10 September 2017 Accepted 11 September 2017

\section{(a) CrossMark}

${ }^{1}$ Global Health, Royal Australasian College of Surgeons, Melbourne, Victoria, Australia

${ }^{2}$ Service Delivery and Safety, World Health Organization, Geneva, Switzerland ${ }^{3}$ Pacific Islands Surgeons Association, Rarotonga, Cook Islands

${ }^{4}$ Australian and New Zealand College of Anaesthetists, Melbourne, Victoria, Australia ${ }^{5}$ Plastic and Oral Surgery, Boston Children's Hospital, Boston, Massachusetts, USA

Correspondence to

Professor Glenn Douglas Guest; glennguest@gmail.com

\section{ABSTRACT}

In 2015, the Lancet Commission on Global Surgery (LCoGS) recommended six surgical metrics to enable countries to measure their surgical and anaesthesia care delivery. These indicators have subsequently been accepted by the World Bank for inclusion in the World Development Indicators. With support from the Royal Australasian College of Surgeons and the Pacific Islands Surgical Association, 14 South Pacific countries collaborated to collect the first four of six LCoGS indicators. Thirteen countries collected all four indicators over a 6-month period from October 2015 to April 2016. Australia and New Zealand exceeded the recommended LCoGS target for all four indicators. Only 5 of 13 countries (38\%) achieved 2-hour access for at least $80 \%$ of their population, with a range of 20\% (Papua New Guinea and Solomon Islands) to over $65 \%$ (Fiji and Samoa). Five of $13(38 \%)$ countries met the target surgical volume of 5000 procedures per 100000 population, with six performing less than 1600 . Four of $14(29 \%)$ countries had at least 20 surgical, anaesthesia and obstetric providers in their workforce per 100000 population, with a range of 0.9 (Timor Leste) to 18.5 (Tuvalu). Perioperative mortality rate was reported by 13 of 14 countries, and ranged from $0.11 \%$ to $1.0 \%$. We believe it is feasible to collect global surgery indicators across the South Pacific, a diverse geographical region encompassing high-income and low-income countries. Such metrics will allow direct comparison between similar nations, but more importantly provide baseline data that providers and politicians can use in advocacy national health planning.

\section{INTRODUCTION}

Five billion of the world's seven billion population lack access to safe, affordable and timely surgical and anaesthesia care. ${ }^{1}$ This leads to preventable mortality, unnecessary disability and uncorrected deformity that negatively impact health and economic activity. $^{2-5}$

The World Health Assembly (WHA) resolution A 68/15 passed in May 2015 addressed the need to 'Strengthen Emergency and

\section{Key questions}

What is already known about this topic?

- In May 2015, the Lancet Commission on Global Surgery recommended six surgical metrics that would enable countries and their ministries of health to measure surgical care delivery and monitor progress.

What are the new findings?

- This is the first time these metrics have been collected from the Asia-Pacific region.

- We also document the collaborative approach undertaken in this region and the lessons learnt regarding the methodology and sustainability of data collection, definition of the indicators, the strengths and weaknesses of these metrics, and how they may be used to achieve change.

\section{Recommendations for policy}

- This collaborative effort has shown that it is possible to collect global surgery indicators across a geographical region.

- Such metrics allow direct comparison between similar nations, and provide baseline data from which providers and politicians can advocate for measurable solutions to improve the safe, timely and affordable access to surgical and anaesthesia care.

Essential Surgical Care and Anaesthesia as a part of Universal Health Coverage' ${ }^{6}$ In order to achieve this in low-income and middle-income countries (LMICs) and improve their ability to deliver emergency and essential surgical care, it is necessary to measure access in terms of capability, capacity, timeliness, safety and affordability. ${ }^{78}$

The Lancet Commission on Global Surgery (LCoGS) recommended six surgical metrics that would enable countries and their ministries of health to measure surgical care 
delivery and monitor progress. ${ }^{1}$ These metrics have been included in WHO's 100 Health Indicators, ${ }^{9}$ and four have already been adopted by the World Bank. ${ }^{10}$

In 2015, the Bangkok Declaration encouraged signatories to propagate the Commission's key messages, promote research on access to safe, affordable and timely surgery, and report on the WHO's and the Commission's recommended surgical indicators. ${ }^{11}$ Subsequently, Asia-Pacific representatives at the 4th Royal Australasian College of Surgeons (RACS) Global Health Symposium, held in association with the LCoGS in Melbourne in October 2015, resolved to obtain data on the first four of six global surgery metrics for countries in their region.

This paper reports on LCoGS indicators collected in the Asia-Pacific region. It also presents the practical challenges in obtaining the data in low-income countries with limited health information technology.

English-speaking countries in the South Pacific were invited to collaborate in the collection of the first four of six LCoGS indicators. To do so, the RACS established a working group through its collegial network with a clinical representative from each country. An information document, containing background information and indicator definitions, and a spreadsheet were distributed via email. The working group was supported by a precollection feasibility survey, an online chat group and regular teleconferences over a 6-month period from October 2015 to April 2016. The representative was asked to seek permission with the appropriate authority in their own country and their data were only included once this permission was granted.

The definition for each indicator was taken from the Global Surgery 2030 report and summarised in table 1. The practical methodology of collecting the LCoGS indicators for each country is presented in table 2 . The methodology was guided by the working group to determine a consensus view where previously unanticipated questions arose or seeking further clarification and advice from LCoGS Commissioners or authors (JM, DW). ${ }^{1}$

Fourteen countries provided data in this collaborative process and a summary of the results is presented in table 3 .

Financial risk protection indicators were not collected, although there were already modelled estimates for many countries in our region, which are included in table 4 . These will likely require adjustment or corroboration by further research.

\section{INDICATOR 1: ACCESS TO TIMELY EMERGENCY AND ESSENTIAL SURGICAL CARE}

This indicator is defined as the "proportion of the population that can access, within two hours, a facility that can do caesarean delivery, laparotomy, and treatment of open fracture (the Bellwether Procedures)'. ${ }^{1}$ The bellwether procedures serve as a proxy for systems, resources and skill sets needed to perform
Table 1 Description of Lancet Commission global surgical indicators

\begin{tabular}{ll}
$\begin{array}{l}\text { Global surgical } \\
\text { indicator }\end{array}$ & Description \\
\hline $\begin{array}{l}\text { Indicator 1: access } \\
\text { to timely essential } \\
\text { surgery }\end{array}$ & $\begin{array}{l}\text { Percentage of the population } \\
\text { who can access, within 2 hours, a } \\
\text { facility capable of performing the } \\
\text { bellwether procedures (caesarean } \\
\text { section, laparotomy and open } \\
\text { fracture management) }\end{array}$ \\
$\begin{array}{ll}\text { Indicator 2: surgical, } \\
\text { anaesthesia and } \\
\text { obstetric density }\end{array}$ & $\begin{array}{l}\text { in surgery, anaesthetics or } \\
\text { obstetrics per 100000 population }\end{array}$ \\
$\begin{array}{l}\text { Indicator 3: surgical } \\
\text { volume }\end{array}$ & $\begin{array}{l}\text { Total number of surgical cases per } \\
100000 \text { population }\end{array}$ \\
$\begin{array}{l}\text { Indicator 4: } \\
\text { perioperative mortality }\end{array}$ & $\begin{array}{l}\text { Deaths occurring after any surgical } \\
\text { procedure and before discharge } \\
\text { from hospital (\%) }\end{array}$ \\
$\begin{array}{l}\text { Indicator 5: risk } \\
\text { of catastrophic } \\
\text { expenditure due to } \\
\text { need for surgical care }\end{array}$ & $\begin{array}{l}\text { Direct out-of-pocket costs from } \\
\text { surgical care exceeding 10\% of } \\
\text { total income or 40\% of remaining } \\
\text { income after food and housing } \\
\text { are accounted for }\end{array}$ \\
$\begin{array}{l}\text { Indicator 6: risk of } \\
\text { impoverishment due to } \\
\text { need for surgical care }\end{array}$ & $\begin{array}{l}\text { need for surgical care resulting } \\
\text { in falling below poverty line of } \\
\text { US\$1.25/day. }\end{array}$ \\
\hline
\end{tabular}

a broad range of essential surgical operations, and correlate with capability of performing other emergency and essential procedures on WHO's Integrated Management for Emergency and Essential Surgical Care list. ${ }^{7}$ Two hours was originally chosen by LCoGS as an estimation of the time from onset of bleeding to death for postpartum haemorrhage. ${ }^{1}$

We considered a hospital to be bellwether-capable if its usual resource allocation allowed it to perform the bellwether procedures the majority of the time. Estimation of the proportion of the population covered was performed by identifying all bellwether-capable facilities and plotting a map to define the 2-hour access zone (table 2). For each hospital, 2-hour access times were dependent on transportation methods and terrain. Population density maps were obtained from government census or surveys to calculate the size and proportion of the total population with access to the bellwethers.

Five of 13 countries $(38 \%)$ reached the LCoGS target of $80 \%$ (table 3 ).

Access to timely essential surgery (indicator 1 ) is in principle an easily understandable metric but one of the more difficult to measure. We found the most reliable data were obtained using local knowledge of the hospitals, the terrain and local transport rather than internet-based maps or satellite population density data. In most instances, regional bellwether hospitals had a small number of roads on which patients could travel and the 2-hour zone on these roads could be marked. Although 


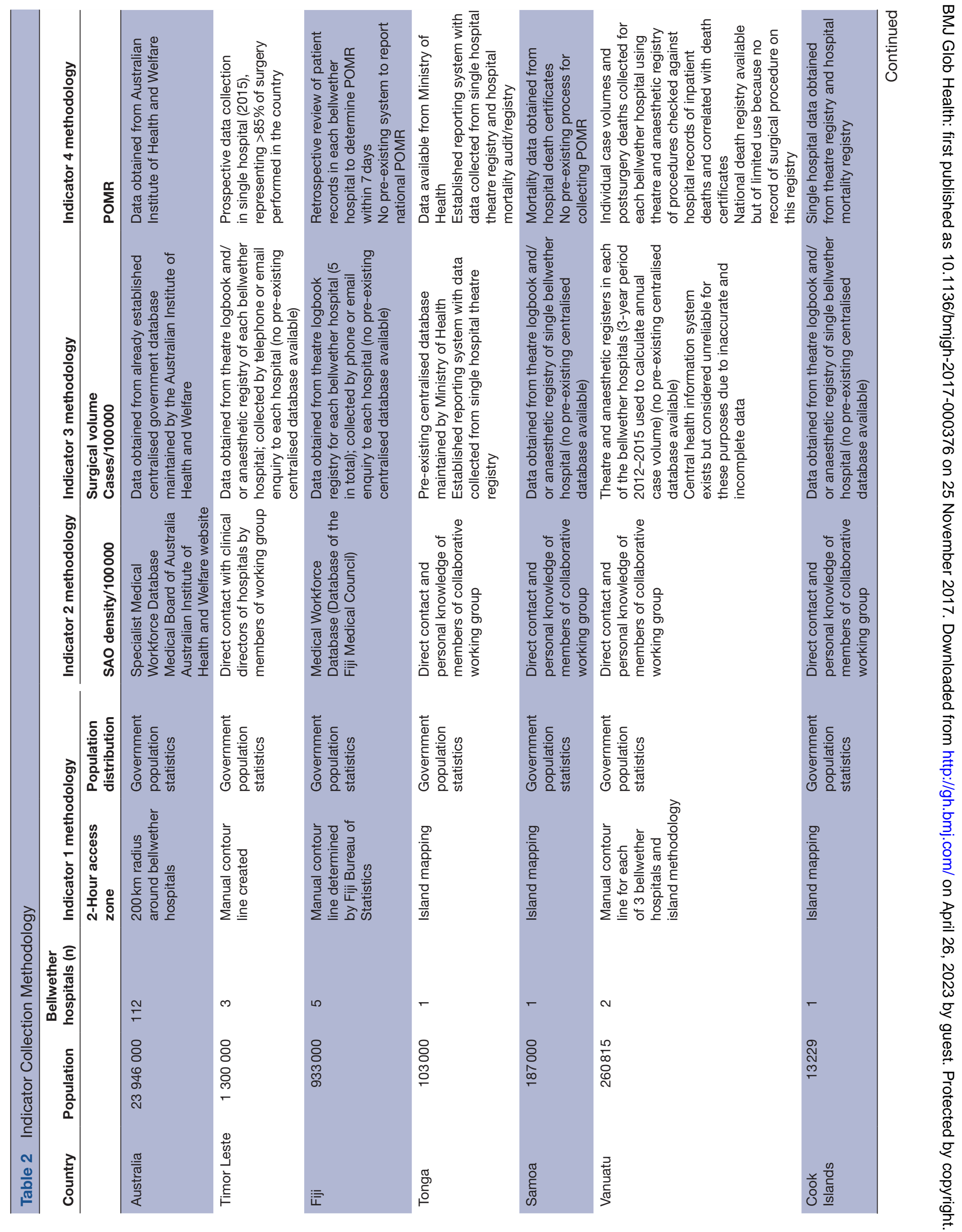




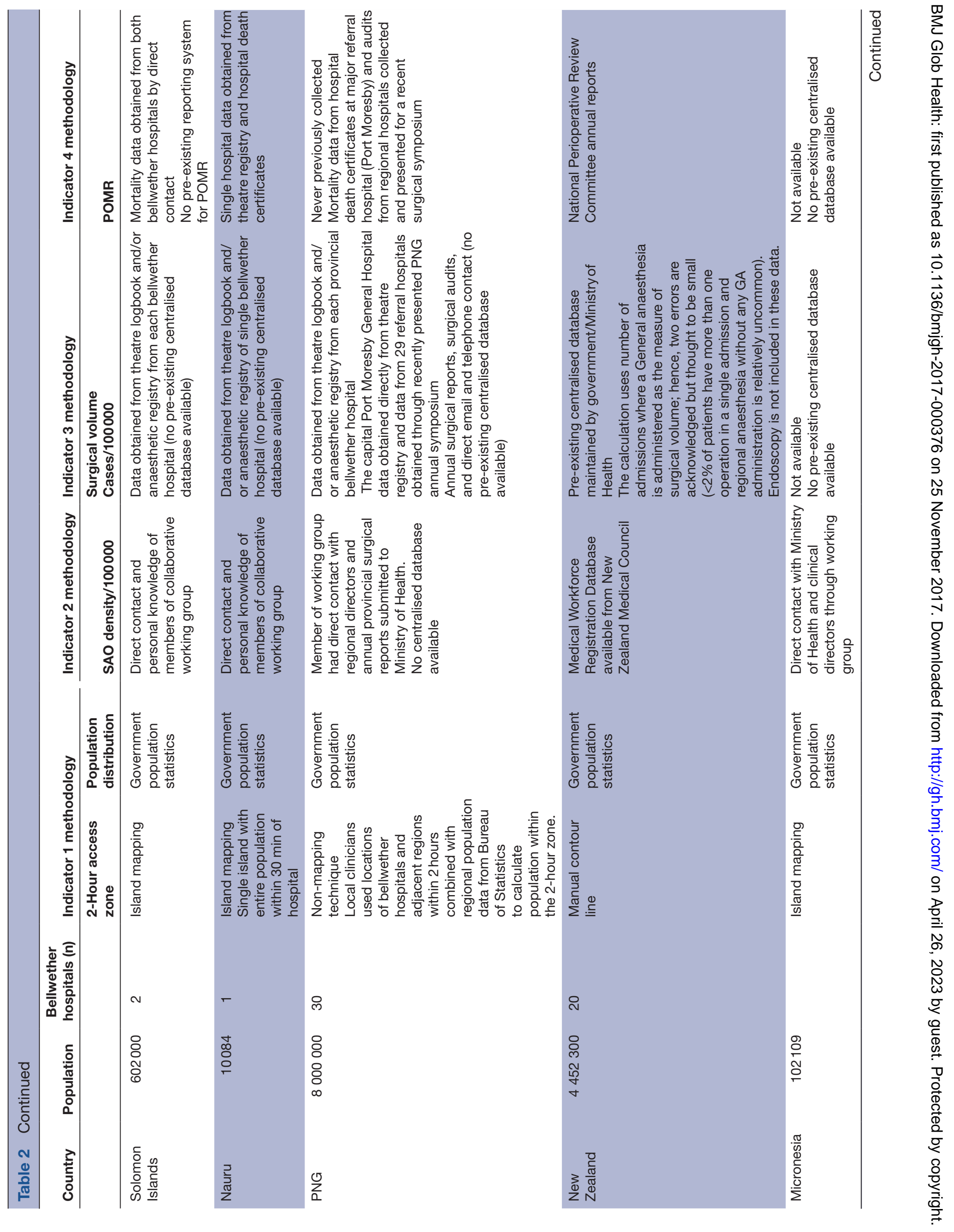




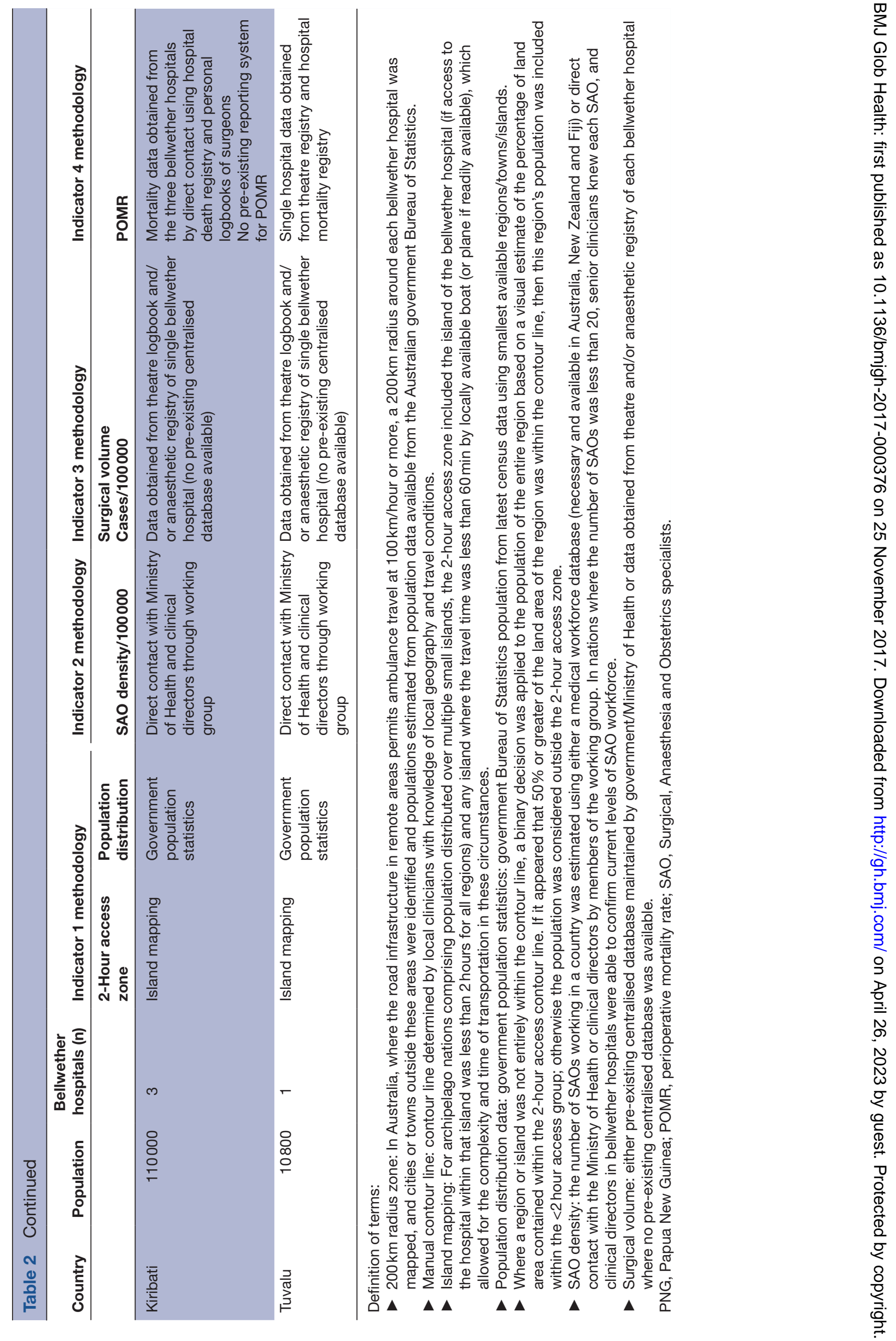


Table 3 Results of global surgical indicators by country

\begin{tabular}{lcllll}
\hline Country & Population & Indicator 1 (\%) & $\begin{array}{l}\text { Indicator 2 } \\
\text { SAO/100 000 }\end{array}$ & $\begin{array}{l}\text { Indicator 3 } \\
\text { Case/100 000 }\end{array}$ & $\begin{array}{l}\text { Indicator 4 } \\
\text { (\%) }\end{array}$ \\
\hline Nauru & & Access <2 hours & SAO density & Surgical volume & POMR \\
\hline Tuvalu & 10084 & 100 & 30 & 7130 & 0.24 \\
\hline Cook Islands & 10837 & 56 & 18.5 & 3417 & 1.0 \\
\hline Micronesia & 13229 & 88 & 22 & 6758 & 0.11 \\
\hline Tonga & 102109 & Not available & 7 & Not available & Not available \\
\hline Kiribati & 103000 & 85 & 14 & 5061 & 0.24 \\
\hline Samoa & 110000 & 65 & 8.2 & 1718 & 0.11 \\
\hline Vanuatu & 187000 & 68 & 1.6 & 1552 & 0.82 \\
\hline Solomon Islands & 260815 & 44 & 3.2 & 1277 & 0.28 \\
\hline Fiji & 602000 & 20 & 2.5 & 868 & 0.46 \\
\hline Timor Leste & 933000 & 67 & 5.8 & 1490 & 0.83 \\
\hline Papua New Guinea & 7300000 & 50 & 0.9 & 433 & 0.84 \\
\hline New Zealand & 4500000 & 20 & 2.3 & 1264 & 0.5 \\
\hline Australia & 23500 & 90 & 43 & 5308 & 0.43 \\
\hline
\end{tabular}

POMR, perioperative mortality rate; SAO, surgical, anaesthesia and obstetrics.

Table 4 World Bank estimated risk of catastrophic expenditure or of impoverishment due to need for surgical or anaesthesia care (http:www.data.worldbank.org/indicator)

\begin{tabular}{|c|c|c|c|}
\hline Country & Population & $\begin{array}{l}\% \text { Risk of } \\
\text { catastrophic } \\
\text { expenditure* } \\
\text { (direct OOP } \\
\text { costs) }\end{array}$ & $\begin{array}{l}\text { \% Risk of } \\
\text { impoverishment } \\
\text { <US\$1.25 per } \\
\text { day } \\
\text { (direct OOP } \\
\text { costs) }\end{array}$ \\
\hline Nauru & 10084 & Not available & Not available \\
\hline Tuvalu & 10837 & 0 & 17 \\
\hline $\begin{array}{l}\text { Cook } \\
\text { Islands }\end{array}$ & 13229 & Not available & Not available \\
\hline Micronesia & 102109 & 31 & 51 \\
\hline Tonga & 103000 & 8 & 16 \\
\hline Kiribati & 110000 & 0 & 34 \\
\hline Samoa & 187000 & 5 & 18 \\
\hline Vanuatu & 260815 & 14 & 37 \\
\hline $\begin{array}{l}\text { Solomon } \\
\text { Islands }\end{array}$ & 602000 & 5 & 57 \\
\hline Fiji & 933000 & 21 & 24 \\
\hline Timor Leste & 1300000 & 16 & 72 \\
\hline $\begin{array}{l}\text { Papua New } \\
\text { Guinea }\end{array}$ & 7500000 & 29 & 56 \\
\hline $\begin{array}{l}\text { New } \\
\text { Zealand }\end{array}$ & 4452300 & 8 & 2 \\
\hline Australia & 23946300 & 5 & 1 \\
\hline Worldwide & 7.1 billion & 44 & 47 \\
\hline
\end{tabular}

${ }^{*}$ Catastrophic expenditure is greater than $10 \%$ of annual income or $40 \%$ of remaining income after food and housing costs. OOP, out-of-pocket costs for surgical care. this process was feasible in smaller countries or regions with a population of one million or less, it would be more challenging and less practical for larger populations with an extensive transport network.

Geography certainly had a major influence on timeliness of access to the bellwether procedures. Some countries such as the Solomon Islands and Vanuatu consist of small island archipelagos spread over vast expanses of the Pacific Ocean, and populations on remote islands had poor access to the bellwethers. Similarly, Timor Leste and Papua New Guinea (PNG) are challenged by regions with mountainous terrain, and limited transport services with consequent low rates of access to the bellwethers. Small island nations where the majority of the population live on a few islands (Nauru, Cook Islands and Tonga) achieved at least $80 \%$ bellwether access within 2 hours.

Plotting bellwether access should assist in national surgical planning. In one country with just $50 \%$ population coverage, $80 \%$ of the population were within 2 hours of the country's five provincial hospitals, but only three of these were bellwether-capable. Hence, upgrading the two non-bellwether-capable hospitals will provide $80 \%$ coverage.

In the future, it would be helpful to measure bellwether access over time and report it in national surgical plans. Shortages of essential supplies, or temporary loss of trained surgical, anaesthesia and obstetrics (SAO) providers, can compromise the ability to deliver a service. In LMICs these challenges mean some hospitals are unable to guarantee the bellwether services all of the time. Attempting to accurately record the proportion of time that the bellwether procedures can be performed would undoubtedly make the collection of this metric too burdensome. However, further research in LMICs on 
the impact of interruptions to service would be valuable in determining the impact of when the bellwethers are not deliverable.

\section{INDICATOR 2: SURGICAL, ANAESTHESIA AND OBSTETRIC WORKFORCE DENSITY}

LCoGS defined SAO workforce density as the "number of specialist surgical, anaesthetic, and obstetric physicians who are working per 100000 population'. This definition excludes non-physician providers such as nurse anaesthetists. We also excluded visiting international specialists who were in a country temporarily, trainees who required direct supervision by a specialist and SAOs who had not provided clinical care in the past year.

The SAO total was gathered from specialist registration boards in larger nations or obtained by each country's representative on the working group in smaller nations who used their knowledge of the workforce if no registry existed (table 2).

Four of $14(29 \%)$ countries reached the LCoGS target of 20 SAOs per 100000 population with a range of 0.9-63.9 (mean 15.9; median 7.6) (table 3).

The SAO density in our region shows marked disparity between countries but generally reflects the true specialist physician workforce and is consistent with other reports from the region. ${ }^{12}$ For most LMICs, there is a considerable shortfall, well below the desired 20-40/100 000. As such, future health workforce planning will need to include SAO providers based on predicted medical specialist graduates and alternative providers. In the Pacific, particularly the smaller island nations, an international visiting workforce often delivers the highly specialised elective procedures. ${ }^{1314}$

We believe it is appropriate that the workforce comprising specialist medical teams is not counted in SAO numbers despite their contribution to surgical volume. However, the exclusion of non-physician SAOs, particularly nurse anaesthetists, does challenge the ability to interpret the metric. Where a country has a significant number of non-physician SAO providers, adhering to the LCoGS definition of SAO density will underestimate the true clinical workforce. We would advocate for reporting this metric, but that each country collects data on all cadres of SAOs and hence recognise the true nature of their workforce. Physician non-specialist and non-physician SAO providers also need to be counted and reported. Timor Leste exemplifies the need to do so, where anaesthesia is largely provided by 23 nurse anaesthetists, and only 3 supervising anaesthesia physician providers. This effect was also evident in PNG and is anticipated to be even more prominent in some countries in Sub-Saharan Africa, where non-physician proceduralists comprise a significant part of the workforce. ${ }^{15-18}$

\section{INDICATOR 3: SURGICAL VOLUME}

Surgical volume (SV) is defined as the number of 'procedures done in an operating theatre, per 100000 population per year, ${ }^{1}$ at bellwether-capable facilities and other surgical facilities. As per the LCoGS definition, a procedure was included if performed in an operating theatre regardless of the type of anaesthesiafor example, endoscopy and cases performed under local anaesthesia. Data were obtained from electronic reporting systems or theatre logbooks when the former was not available. Cases performed by or under the supervision of non-SAO specialists (eg, visiting teams) were included, although these visiting specialists were not counted for SAO density.

Local representatives identified all operating facilities. All facilities prospectively maintained a written or electronic theatre logbook or registry. In some countries, the Ministry of Health already collected these data and made it available to the authors. Where no pre-existing reporting process was available, the theatre logbook totals were individually collated over a defined period and an annual SV was calculated and subsequently converted to an SV density using the population values reported by the World Bank. The authors are confident that this process captures the majority of all surgical procedures in each country. Although minor procedures in private facilities may not have been identified, they are expected to be a relatively minor contribution to surgical services in the countries of this region.

Five of $13(38 \%)$ countries reached the Commission target of 5000 surgical procedures per 100000 population, with a reported range of 433-10156 (mean 3572; median 1718) as represented in table 3 .

SV was designed to reflect health system capacity to deliver emergency and essential surgical/anaesthesia care. Some countries already had a system of regular reporting of surgical activity or volume in place, while for others this was a labour-intensive process requiring manual collection of data from theatre logbooks in each operating facility.

In smaller nations, numbers are small enough to enable accurate data collection, but in larger nations this approach is unlikely to be practical or sustainable. To achieve a sustainable and minimum standard of reporting, each country must maintain a registry of all operating facilities, and mandate recording of all procedures in a theatre logbook with annual reporting of surgical activity by urgency, age range, gender, procedure group/specialty and method of anaesthesia. This standard has already been adopted by WHO.

\section{INDICATOR 4: PERIOPERATIVE MORTALITY RATE}

Perioperative mortality rate (POMR) is defined as 'all-cause death rate before discharge in patients who have had a procedure in an operating theatre, divided by the total number of procedures, presented as a percentage'. ${ }^{19-21}$ This is a critical safety metric, which has been previously adopted by the WHO Safe Surgery Saves Lives initiative. ${ }^{22-24}$ 
In our region there was large variation in collection of mortality data. Some hospitals kept a reliable mortality register. In these instances they were used to perform a case review and determine which patients had a procedure during that inpatient stay. If no existing mortality register existed, then POMR was calculated using a prospective method over a 6 -month period (eg, Timor Leste). The variations for each country are reported in table 2.

POMR was collected for $13 / 14$ countries and ranged from $0.11 \%$ to $1.0 \%$ (table 3 ).

WHO and LCoGS recommend POMR be recorded as death before discharge after a procedure performed in an operating room. ${ }^{122-24}$ It is not practical in LMICs to attempt to measure POMR at 30 days because of the challenges of follow-up. The reported correlation between the POMR at 7 days and POMR at 30 days, even in LMICs, gives some confidence that POMR measured only before discharge is reliable and interpretable. ${ }^{2526}$ We would also argue that any country or health service that is providing a surgical service but does not know whether patients survive to leave hospital is seriously deficient in providing quality assurance to the populations they serve.

New Zealand and Tonga were the first countries in this region to report POMR nationally. ${ }^{19}$ In this region the POMR varies from the lowest result of $0.11 \%$ (Cook Islands) to the highest of $1.0 \%$ (Tuvalu). We interpret these data to indicate a suitably high standard of surgical and anaesthetic care, but there is still an almost tenfold variation between some countries. Further study will need to be done to help interpret this result and tease out the relative contributions of quality of surgery and anaesthesia affecting POMR compared with the many other factors such as age, case mix, operation type, American Society of Anaesthesiologists (ASA) grade and delayed presentations with advanced pathology.

Australia and New Zealand have already reported the influence of age and urgency, ${ }^{27}$ while New Zealand has reported on low-risk procedures and ASA status, as well as some specific procedural groups. ${ }^{28-30}$

In Australia and New Zealand the operation urgency is an influential risk factor, with emergency and elective POMRs varying tenfold. ${ }^{27-30}$ Many LMICs have much higher proportions of emergencies than electives, and where this is so they should perhaps compare emergency and elective POMRs separately. In some Pacific countries, the POMR could vary by a factor of 2 depending on whether SV includes low-risk endoscopy and local anaesthetic cases. To make safety and quality comparisons, POMR should perhaps be based on case mix and include specific condition or procedure mortalities, such as emergency laparotomy. It is also important to include obstetric and gynaecological cases as these form a considerable proportion of the SV in LMICs, have a low mortality, and consequently their omission from POMR rate could skew the metric towards higher rates.

Once POMR is reported, there is an opportunity for each nation to use its rate to measure improvements in surgical and anaesthesia care. In the future POMR may be reported by urgency and procedure group at least to enable benchmarking between countries. However initially effort must go into countries learning to report their own POMRs, and monitor improvements in the delivery of surgical and anaesthesia care through this safety metric.

\section{INDICATORS 5 AND 6: FINANCIAL RISK PROTECTION}

We did not collect data on the financial risk protection indicators (table 4), having extracted these for the Pacific Region from the World Bank's indicators on catastrophic expenditure and impoverishment by the need for surgery. ${ }^{10}$ The rates range from $0 \%$ to $30 \%$ for catastrophic expenditure and from $1 \%$ to $72 \%$ for impoverishment. For impoverishment, four countries-Micronesia, PNG, Solomon Islands and Timor Leste-were above the worldwide average of $44 \%$.

Healthcare payments predicted from modelling in the Asia-Pacific region appear to be high, ${ }^{31-33}$ so national health plans need to address how healthcare, including surgery and anaesthesia, can be provided affordably. We plan further studies to assess the actual, as opposed to modelled, risk of catastrophic expenditure and impoverishment incurred through the need for surgery.

\section{CHALLENGES OF COLLECTING GLOBAL SURGICAL METRICS AND SUCCESS THROUGH COLLABORATION}

There is considerable diversity between nations whose populations range from 10000 in Nauru to 7.5 million in PNG, and 24 million in Australia. Our precollection survey indicated that no nation had a system in place that would enable these data to be reported immediately. Each country perceived that at least one or more of the indicators would be challenging to collect and would require significant individual effort to obtain the data. The authors observed that collaboration between nations provided both motivation and assistance during the data collection process, resulting in 13 of 14 countries achieving the first four Lancet Commission global surgery indicators.

This paper demonstrates the feasibility and benefits of a collaborative approach of collecting LCoGS indicator data in the South Pacific despite the challenges presented by diverse geography, population density, and within low-income countries a lack of infrastructure. The success was in part a result of many years of partnership between RACS and the Pacific Island countries in surgical training and provision of specialist surgical services in the region. ${ }^{13} 14$

\section{STRIVING TOWARDS UNIVERSAL ACCESS TO EMERGENCY AND ESSENTIAL CARE}

In order to realise the WHA's resolution A 68/15 on universal access to emergency and essential care, 
local advocacy must include surgery and anaesthesia in national health plans as has occurred in PNG. ${ }^{34}$

The metrics themselves should inspire each nation to develop a sustainable reporting system that will inform planning for surgery nationally. The effectiveness of interventions designed to improve surgical and anaesthesia care delivery can be measured using the current indicators as a baseline.

Only then will there be progress towards universal access to safe, affordable surgical and anaesthesia care when needed, and a strengthening of Asia-Pacific health systems.

\section{CONCLUSION}

This is the first report of a regional approach to collecting the Lancet global surgical indicators. Data collection from 14 nations has led to a greater understanding of access to timely, safe and affordable surgery in our region and globally.

This report also demonstrates the practicality of collecting LCoGS indicators across a diverse range of nations and should act as encouragement for other nations and regions to take up the challenge. Our experience with this collaborative approach suggests alliances with regional organisations and professional bodies can be influential. Specialty colleges and associations have an opportunity to provide leadership, advocacy and promoting further research into global surgery.

Ministries of health should use these metrics to help formulate their national health plans, and report them to WHO to provide a local and regional perspective as to how surgical care delivery is contributing to the goal of universal health coverage.

Contributors GDG, EM, WP and SK were responsible for coordination of data collection and analysis. VT, JP, PP, JH, JT, DP, EV, BL, NT, JK, BO, DT, LW, SM and KT collected data for their respective countries. All authors contributed to the key messages, conclusions, recommendations, writing and editing of the manuscript. GDG has full access to all the data in the study and had final responsibility for the decision to submit for publication.

Competing interests None declared.

Provenance and peer review Not commissioned; externally peer reviewed.

Data sharing statement Additional data are available on request.

Open Access This is an Open Access article distributed in accordance with the Creative Commons Attribution Non Commercial (CC BY-NC 4.0) license, which permits others to distribute, remix, adapt, build upon this work non-commercially, and license their derivative works on different terms, provided the original work is properly cited and the use is non-commercial. See: http://creativecommons.org/ licenses/by-nc/4.0/

(c) Article author(s) (or their employer(s) unless otherwise stated in the text of the article) 2017. All rights reserved. No commercial use is permitted unless otherwise expressly granted.

\section{REFERENCES}

1. Meara JG, Leather AJ, Hagander L, et al. Global surgery 2030: evidence and solutions for achieving health, welfare, and economic development. Lancet 2015;386:569-624.

2. Rose J, Weiser TG, Hider P, et al. Estimated need for surgery worldwide based on prevalence of diseases: a modelling strategy for the WHO Global health estimate. Lancet Glob Health 2015;3 Suppl 2:S13-S20.
3. Lozano R, Naghavi M, Foreman K, et al. Global and regional mortality from 235 causes of death for 20 age groups in 1990 and 2010: a systematic analysis for the Global burden of disease study 2010. Lancet 2012;380:2095-128.

4. Murray CJ, Vos T, Lozano R, et al. Disability-adjusted life years (DALYs) for 291 diseases and injuries in 21 regions, 1990-2010: a systematic analysis for the Global burden of disease study 2010. Lancet 2012;380:2197-223.

5. Vos T, Flaxman AD, Naghavi M, et al. Years lived with disability (YLDs) for 1160 sequelae of 289 diseases and injuries 1990-2010: a systematic analysis for the Global burden of disease study 2010. Lancet 2012;380:2163-96.

6. Price R, Makasa E, Hollands M. World health assembly resolution WHA68.15: "strengthening emergency and essential surgical care and anesthesia as a component of universal health coverage" addressing the public health gaps arising from lack of safe, affordable and accessible surgical and anesthetic services. World $J$ Surg 2015;39:2115-25.

7. WHO Integrated Management for Emergency and Essential Surgical Care (IMEESC) toolkit. 2016 http://www.who.int/surgery/ publications/imeesc/en/index.html (accessed 24Jun 2016).

8. Debas HT, Donkor P, Gawande A, et al. Disease Control Priorities Essential Surgery. Third Edition: Volume1. Washington, DC: World Bank. (C) World Bank 2015, 2015. https://openknowledge.worldbank. org/handle/10986/21568 License: CC BY 3.0 IGO.

9. WHO. Global reference list of 100 core health indicators. 2016 http:// www.who.int/healthinfo/indicators/2015/en/ (accessed 14 Jul 2016).

10. WorldBank. Indicators (Health).http://data.worldbank.org/ indicator(accessed5 Oct 2016).

11. McQueen KA, Coonan T, Derbew M, et al. The 2015 Bangkok Global surgery declaration: a call to the Global health community to promote implementation of the world health assembly resolution for surgery and anaesthesia care. World J Surg 2017;41:7-9.

12. Cooper MG, Wake PB, Morriss WW, et al. Global safe anaesthesia and surgery initiatives: implications for anaesthesia in the Pacific region. Anaesth Intensive Care 2016;44:420-4.

13. Watters DA, Ewing $\mathrm{H}$, McCaig $\mathrm{E}$. Three phases of the Pacific islands project (1995-2010). ANZ J Surg 2012;82:318-24.

14. Guest GD, Scott DF, Xavier JP, et al. Surgical capacity building in Timor-Leste: a review of the first 15 years of the Royal Australasian college of surgeons-led Australian aid programme. ANZ J Surg 2017;87:436-40.

15. Ulisubisya MM. The critical condition of anaesthesia provision in low-income and middle-income countries. Lancet Glob Health 2016;4:e597-e598.

16. O'Flynn E, Andrew J, Hutch A, et al. The specialist surgeon workforce in east, central and Southern Africa: a situation analysis. World J Surg 2016;40:2620-7.

17. Grimes CE, Mkandawire NC, Billingsley ML, et al. The costeffectiveness of orthopaedic clinical officers in Malawi. Trop Doct 2014;44:128-34.

18. Lewallen S, Etya'ale D, Kello AB, et al. Non-physician cataract surgeons in Sub-Saharan Africa: situation analysis. Trop Med Int Health 2012;17:1405-8.

19. Watters DA, Hollands MJ, Gruen RL, et al. Perioperative mortality rate (POMR): a global indicator of access to safe surgery and anaesthesia. World J Surg 2015;39:856-64.

20. Perioperative Mortality Review Committee. Inaugural report of Perioperative Mortality in New Zealand.POMRC. Wellington: Health Quality and Safety Commission New Zealand, 2011.

21. Perioperative Mortality Review Committee (2012). Perioperative Mortality in New Zealand, Second Report of the Perioperative Review Committee,POMRC. Wellington: Health Quality and Safety Commission, 2012

22. World Alliance for Patient Safety. Global patient safety challenge 2007-08: safe surgery saves lives. Geneva: World health organisation, 2007. http://www.who.int/patientsafety/challenge/ safe.surgery/en/. (accessed Jul 2013).

23. Haynes AB, Weiser TG, Berry WR, et al. A surgical safety checklist to reduce morbidity and mortality in a global population. $N$ Engl J Med 2009;360:491-9.

24. de Vries EN, Hollmann MW, Smorenburg SM, et al. Development and validation of the suRgical patient safety system (SURPASS) checklist. Qual Saf Health Care 2009;18:121-6.

25. Ariyaratnam R, Palmqvist CL, Hider P, et al. Toward a standard approach to measurement and reporting of perioperative mortality rate as a global indicator for surgery. Surgery 2015;158:17-26.

26. Palmqvist CL, Ariyaratnam R, Watters DA, et al. Monitoring and evaluating surgical care: defining perioperative mortality rate and standardising data collection. Lancet 2015;385 Suppl 2:s27:S27. 
27. Watters DA, Babidge WJ, Kiermeier A, et al. Perioperative mortality rates in Australian public hospitals: the influence of age, gender and urgency. World J Surg 2016;40:2591-7.

28. Perioperative Mortality Review Committee. Third report of the perioperative mortality review committee POMRC. Wellington: Health Quality and Safety Commission New Zealand, 2013.

29. Perioperative Mortality Review Committee. Fourth report of the perioperative mortality review committee POMRC. Wellington: Health Quality and Safety Commission New Zealand, 2015.

30. Perioperative Mortality Review Committee. Fifth report of the perioperative mortality review committee POMRC. Wellington: Health Quality and Safety Commission New Zealand, 2016.
31. Shrime MG, Dare A, Alkire BC, et al. A global country-level comparison of the financial burden of surgery. Br J Surg 2016;103:1453-61.

32. Shrime MG, Dare AJ, Alkire BC, et al. Catastrophic expenditure to pay for surgery worldwide: a modelling study. Lancet Glob Health 2015;3 Suppl 2:S38-S44.

33. Reddy SR, Ross-Degnan D, Zaslavsky AM, et al. Health care payments in the Asia Pacific: validation of five survey measures of economic burden. Int J Equity Health 2013;12:49.

34. Dare AJ, Lee KC, Bleicher J, et al. Prioritizing surgical care on National health agendas: a qualitative case study of papua New Guinea, Uganda, and Sierra Leone. PLoS Med 2016;13:e1002023. 